\title{
Cost-effectiveness of umeclidinium/ vilanterol combination therapy compared to tiotropium monotherapy among symptomatic patients with chronic obstructive pulmonary disease in the UK
}

Yogesh Suresh Punekar ${ }^{1 *}$, Graeme Roberts ${ }^{2}$, Afisi Ismaila ${ }^{3,4}$ and Martin O'Leary ${ }^{2}$

\begin{abstract}
Background: The cost-effectiveness of umeclidinium bromide-vilanterol (UMECNI) versus tiotropium monotherapy in the UK was assessed using a UMECNI treatment-specific economic model based on a chronic obstructive pulmonary disease (COPD) disease-progression model.

Methods: The model was implemented as a linked-equation model to estimate COPD progression and associated health service costs, and its impact on quality-adjusted life years (QALYs) and survival. Statistical risk equations for clinical endpoints and resource use were derived from the ECLIPSE and TORCH studies, respectively. For the selected timeframe (1-40 years) and probabilistic analysis, model outputs included disaggregated costs, total costs, exacerbations, life-years and QALYs gained, and incremental cost-effectiveness ratios (ICERs).

Results: Random-effects meta-analysis of tiotropium comparator trials estimated treatment effect of UMECNI as $92.17 \mathrm{~mL}$ (95\% confidence interval: 61.52, 122.82) in forced expiratory volume in $1 \mathrm{~s}$. With this benefit, UMEC/ $\mathrm{VI}$ resulted in an estimated annual exacerbation reduction of 0.04 exacerbations/patient and 0.36 life years gained compared to tiotropium over patient lifetime. With an additional $0.18 \mathrm{QALY} /$ patient and an additional lifetime cost of $£ 372$ /patient at price parity, the incremental cost effectiveness ratio (ICER) of UMECNI compared to tiotropium was $£ 2088 /$ QALY. This ICER increased to $£ 17,541 /$ QALY when price of UMECNI was increased to that of indacaterol plus tiotropium in separate inhalers. The ICER improved when model duration was reduced from patient lifetime to 1 or 5 years, or when treatment effect was assumed to last for 12 months following treatment initiation.
\end{abstract}

Conclusion: UMECNI can be considered a cost-effective alternative to tiotropium at a certain price.

Keywords: Chronic obstructive pulmonary disease, Cost-effectiveness, Tiotropium, Umeclidinium/vilanterol JEL Code: H5 National Government Expenditures and Related Policies.

\section{Background}

Chronic obstructive pulmonary disease (COPD), a common preventable and treatable disease, is characterised by persistent and progressive airflow limitation. It

\footnotetext{
*Correspondence: yogesh.q.punekar@gsk.com

${ }^{1}$ Value Evidence and Outcomes, GlaxoSmithKline R\&D, Stockley Park, Uxbridge UB11 1BT, UK

Full list of author information is available at the end of the article
}

is associated with an increased chronic inflammatory response in the lungs to noxious stimuli [1]. It is ranked by the World Health Organisation (WHO) as the fourth leading cause of death worldwide. In 2011, as estimated by the WHO, there were 2.96 million deaths worldwide attributed to COPD [2, 3]. According to data from the quality and outcomes framework report, the prevalence of diagnosed COPD is $1.6 \%$ (estimated 819,524 people) 
in the United Kingdom; however, an estimated 3 million people have COPD [4].

Globally, the economic impact of COPD is reflected in the $3.3 \%$ disability-adjusted life years (DALYs) reported in the year 2011 by the WHO [5] and the high percentage of patients (nearly $40 \%$ ) who are forced to discontinue work [6]. Early treatment of COPD involves the use of long-acting muscarinic antagonists (LAMAs) such as tiotropium, glycopyrronium, and aclidinium or long-acting $\beta 2$-agonist (LABA) monotherapy such as formoterol, salmeterol, and indacaterol or combination therapy, as necessary. Co-administration of LAMAs and LABAs is more effective in managing stable COPD than either drug class alone, as studies indicate improved lung function, symptoms, and health status with the former [7-9]. The Global Initiative for Chronic Obstructive Lung Disease (GOLD) guidelines recommend the use of a combination of long-acting bronchodilators with differing mechanisms of action if monotherapy is insufficient to control the symptoms of COPD [1]. A second bronchodilator may be considered in moderate COPD to optimise symptom benefit $[1,10]$ whilst avoiding the risk of side effects associated with dose escalation of a single bronchodilator [10]. However, combination treatment in separate inhalers may potentially lead to other challenges such as lower adherence/persistence and suboptimal outcomes [11, 12].

Umeclidinium bromide-vilanterol (UMEC/VI) is a new fixed-dose LAMA/LABA combination (Anoro ${ }^{\circledR}$ ) indicated as maintenance bronchodilator treatment in patients with COPD. It is available at a delivered dose of 55/22 $\mu \mathrm{g}$ once daily in a novel dry-powder inhaler $\left(\right.$ Ellipta $\left.^{\circledR}\right)$. In the European Union, it is approved as maintenance bronchodilator treatment to relieve symptoms in adult patients with COPD. The safety and efficacy of UMEC/VI has been established through a clinical development programme enrolling more than 8000 subjects with COPD. Three active-comparator phase 3a studies (DB2113360, DB2113374, ZEP117115) [13, 14] in this programme evaluated the efficacy of UMEC/VI combination therapy compared with tiotropium. These studies have demonstrated that UMEC/VI provides significant improvements in lung function compared to tiotropium which has gained worldwide acceptance as a first-line, once-daily maintenance therapy for patients with COPD $[1,15]$. UMEC/VI along with other fixed dual bronchodilator combinations may present a new class of initial maintenance treatments in COPD.

Treatment costs are an important consideration in chronic diseases such as COPD. With the increasing number of LAMAs and LAMA/LABA combination therapies in the market, treatment costs are likely to be a major concern to payers. The objective of this study was to assess the cost-effectiveness of UMEC/VI compared with tiotropium monotherapy from the UK National Health Services (NHS) perspective.

\section{Methods}

\section{COPD disease-specific model}

The economic model used in this evaluation was adapted from a COPD disease model published elsewhere [16]. The disease model itself was based on a conceptual model of disease progression. This conceptual model provided a framework to describe relationships between different demographic and clinical parameters, disease progression, and health outcomes (Fig. 1a) [17]. This association was estimated using data from the Evaluation of COPD Longitudinally to Identify Predictive Surrogate Endpoints (ECLIPSE) study [18] and the resulting risk equations were connected through a model that predicted utility, survival, and health-care resource use in future $[16,19]$ (Fig. 1b; Additional file 1).

\section{Model description}

Input parameters in the COPD disease model include age, gender distribution, body mass index, cardiovascular and other comorbidities, prior exacerbation history, smoking status and health status measured by the SGRQ or St George's Respiratory Questionnaire for COPD (SGRQ-C). The model also requires baseline estimates for proportions of patients with dyspnoea, cough and sputum, exacerbation rate, forced expiratory volume in one second (FEV1), and exercise capacity measured by the 6-min walk test (6MWT). One or more of these can either be input directly in the model or predicted using other available parameters $[16,19]$.

In each model cycle, based on the statistical risk equations (Additional file 1) and by using the baseline clinical and demographic information of the target population, the model estimates the number of moderate and severe exacerbations, predicted FEV1 in millilitres, the proportion of patients with dyspnoea or cough and sputum symptoms most days per week, 6MWT distance in metres, and SGRQ total score (Fig. 1b). These parameter estimates then predict SGRQ scores, survival, and resource use in that model cycle. All of these parameters have been shown to be good predictors of future disease progression in COPD and are therefore used as input parameters in the subsequent cycles [17]. For each time period, the predicted SGRQ scores were transformed to the EQ-5D utility based on a published algorithm [20]. The risk equations providing annual rates were further adjusted to estimate outcomes at specific cycle lengths.

\section{UMEC/VI treatment-specific economic model}

In order to fit this model to UMEC/VI clinical programme, a 6-month trial period was added at the start. It 


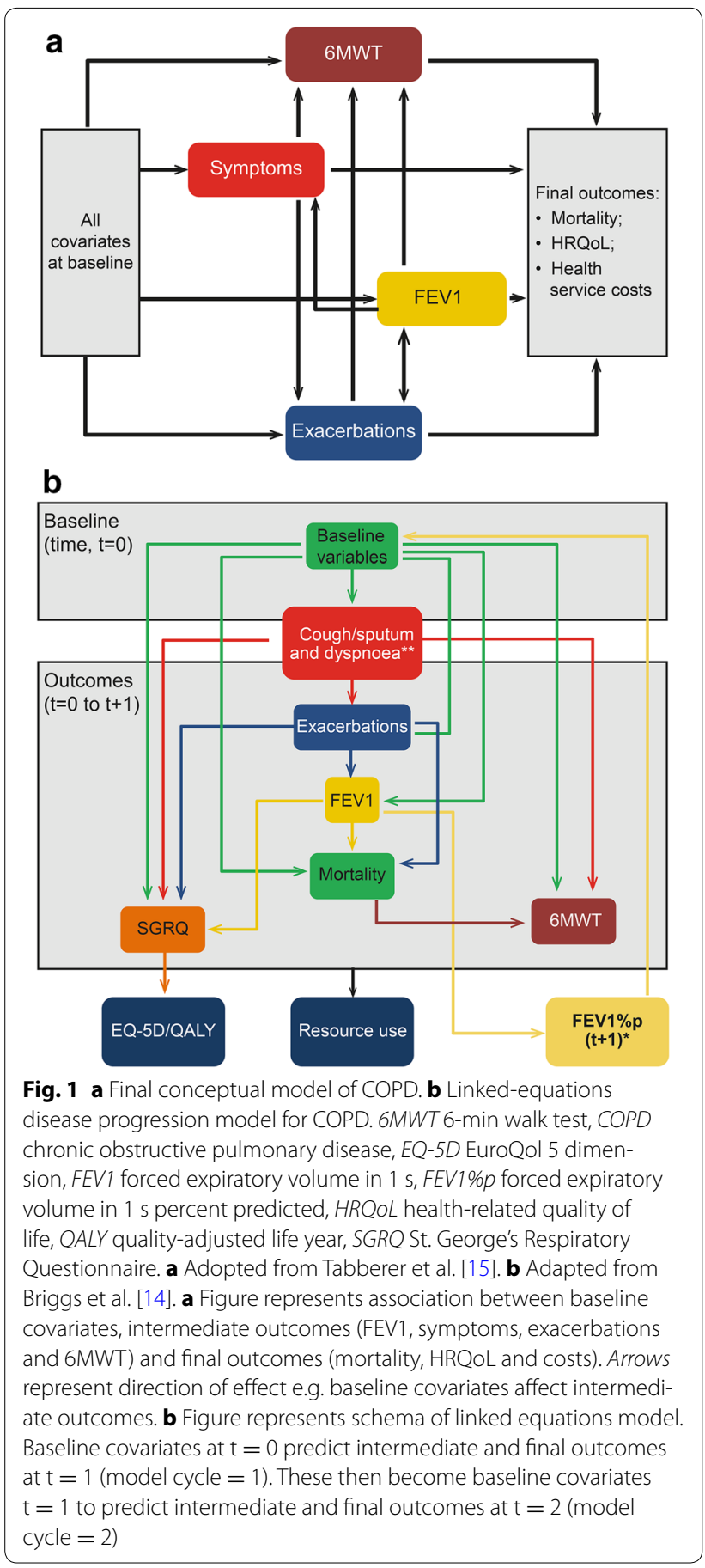

was implemented as two 3-month cycles, and 6-monthly cycles thereafter for the remainder of the model timeframe. In the base case, the model time frame was assumed to be over the lifetime of the patients. Separate scenario analyses were conducted to assess the benefit of UMEC/VI over shorter time frames of 1 year (Scenario A) and 5 years (Scenario B).

\section{Model inputs}

The baseline cohort used in the model represented the UMEC/VI phase 3 a trial population derived using an integrated analysis of four pivotal trials (DB2113360, DB2113361, DB2113373, DB2113374) [13, 21, 22]. In instances where such information was not available from the UMEC/VI clinical programme, baseline estimates from ECLIPSE [18] were used.

The treatment effect was expressed as the difference in change from baseline in FEV1 at 24 weeks between UMEC/VI and tiotropium. FEV1 was selected as it was the primary endpoint in UMEC/VI clinical trial programme. The treatment effect was estimated by a random-effects meta-analysis of tiotropium comparator trials from the UMEC/VI phase 3a clinical programme (DB2113360, DB2113374, ZEP117115) [13, 14]. Trials results demonstrated that UMEC/VI was superior to tiotropium on FEV1 indicating that it provides superior bronchodilation to tiotropium. The treatment benefit of UMEC/VI over tiotropium was assumed for the lifetime of the patient in the base case. A separate scenario analysis was conducted (Scenario C) assuming that the treatment effect lasts for a period of 12 months from treatment initiation, based on the results of UMEC/VI safety study (DB2113359) [23].

\section{Costs}

The perspective adopted for costs was that of the National Health Service (NHS) in England and Wales. The reference year used for costs was 2011-2012. Productivity losses, although significant, were omitted because of this choice of perspective.

Cost of treatment with tiotropium was obtained from the British National Formulary (BNF March 2014) and was estimated to be $£ 33.50$ for a 30 -day supply [24]. The cost of UMEC/VI was assumed to be equivalent to tiotropium in the base case and was increased to be equivalent to the price of indacaterol plus tiotropium in separate inhalers (£62.76) in the sensitivity analyses. Resourceuse costs were estimated using NHS reference costs for 2013-2014 and are displayed in Table 1.

\section{Cost-effectiveness analyses}

The results of the cost-effectiveness analysis are reported here in the form of incremental cost per quality-adjusted life year (QALY) gained. Costs and outcomes were calculated separately for each treatment alternative over the model timeframe and then discounted at $3.5 \%$ per annum [25]. Uncertainty around patient level inputs (first order) and risk-equation estimates (second order) was further explored using probabilistic sensitivity analysis with 5000 iterations. The range of values and the distributions used in the probabilistic sensitivity analyses are 
Table 1 Resource use costs estimated using NHS reference costs for 2011-2012

\begin{tabular}{lll}
\hline Resource use & Costs & Source \\
\hline Cost per day in ICU & $£ 1190.29$ & NHS National Schedule of Reference Costs 2013-2014 \\
Cost per day in general ward & $£ 514.00$ & NHS National Schedule of Reference Costs 2013-2014 \\
Per hospitalisation (COPD Related) & $£ 1897.00$ & NHS National Schedule of Reference Costs 2013-2014 \\
ER visit & $£ 123.74$ & NHS National Schedule of Reference Costs 2013-2014 \\
Hospital outpatient visit & $£ 150.00$ & NHS National Schedule of Reference Costs 2013-2014 \\
Physician visits & Cost (2012£) & \\
Daytime home visit & $£ 114.00$ & Personal Social Service Research Unit-Unit Costs of Health and Social Care 2012 \\
Night-time home visit & $£ 114.00$ & Assumed the same as daytime visit \\
Visit to physician's office & $£ 67.00$ & Personal Social Service Research Unit-Unit Costs of Health and Social Care 2012
\end{tabular}

ER emergency room, COPD chronic obstructive pulmonary disease, ICU intensive care unit, NHS National Health Service

presented in Table 2 for patient level inputs and in Additional file 1 for risk equation estimates.

\section{Results}

\section{Baseline cohort}

The baseline demographic and clinical parameters used in the model are displayed in Table 2. Cohort characteristics assumed that all patients were symptomatic (modified Medical Research Council scale [mMRC] score $\geq 2$ ) and broadly comparable to symptomatic patients in the primary care setting in the United Kingdom [26].

\section{UMEC/VI treatment effect}

The random-effects meta-analysis of tiotropium comparator trials estimated the treatment effect of UMEC/VI to be 92.17 (maximum likelihood; $95 \%$ confidence interval: 61.52, 122.82; Fig. 2a) [13, 14].

Table 2 Model baseline population parameters

\begin{tabular}{|c|c|c|c|}
\hline Parameter & Values and $\%$ of patients & Standard error ${ }^{\mathbf{a}}$ & Distributions used in the PSA \\
\hline \multicolumn{4}{|l|}{ Gender } \\
\hline Female (\%) & $32.0 \%$ & $1.15 \%$ & Beta \\
\hline Mean age (years) & 63.3 & 0.1 & Normal \\
\hline \multicolumn{4}{|l|}{$\mathrm{BMI}$} \\
\hline Low (\%) & $10.4 \%$ & $0.84 \%$ & Beta \\
\hline Medium (\%) & $65.1 \%$ & - & - \\
\hline High (\%) & $24.5 \%$ & $1.02 \%$ & Beta \\
\hline Any CVD comorbidity (\%) & $43.5 \%$ & $1.13 \%$ & Beta \\
\hline Without comorbidity (\%) & $56.5 \%$ & - & - \\
\hline Any other comorbidity (\%) & $77.3 \%$ & $1.07 \%$ & Beta \\
\hline History of exacerbation, 1 or more (\%) & $46.2 \%$ & $1.21 \%$ & Beta \\
\hline mMRC score $\geq 2(\%)$ & $100.0 \%$ & & - \\
\hline Current smokers (\%) & $49.0 \%$ & $1.16 \%$ & Beta \\
\hline Height (cm) & 169.0 & 0.1 & Normal \\
\hline Fibrinogen $(\mu \mathrm{g} / \mathrm{mL})$ & 458.8 & 102.4 & Gamma \\
\hline Number of exacerbations in prior year & 0.50 & 0.01 & Gamma \\
\hline Proportion of prior exacerbations that are severe & 20.0 & & Gamma \\
\hline Starting SGRQ score & 49.1 & 0.5 & Normal \\
\hline Starting FEV1 \%p (\%) & $47.7 \%$ & $0.2 \%$ & Beta \\
\hline 6-min walk distance (m) & 378.3 & 2.9 & Normal \\
\hline
\end{tabular}

$B M I$ body mass index, CVD cardiovascular disease, ECLIPSE Evaluation of COPD Longitudinally to Identify Predictive Surrogate Endpoints, FEV1\%p forced expiratory volume in $1 \mathrm{~s}$ percent predicted, $m M R C$ modified Medical Research Council dyspnoea scale, PSA probabilistic sensitivity analysis, SE standard error, SGRQ St. George's Respiratory Questionnaire

a SE Calculated or assumed based on availability of data 


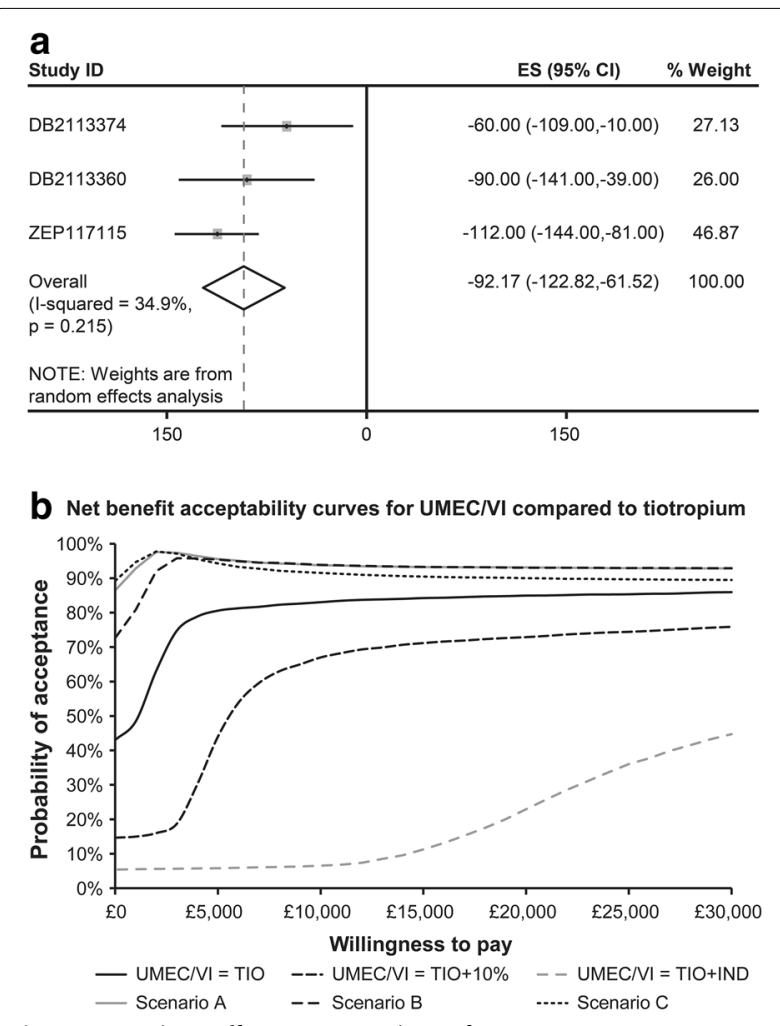

Fig. 2 a Random-effects meta-analysis of tiotropium comparator trials. b Probabilistic sensitivity analysis: net benefit acceptability curves for UMECNI compared with tiotropium. Cl confidence interval, ES effect size, IND indacaterol, TIO tiotropium, UMECNI umeclidinium bromide/vilanterol. DB2113374 and DB2113360 [11]; ZEP117115 [12]. a Effect size (ES) represents increment in FEV1 ( $\mathrm{ml}$ ) of UMECNI compared to tiotropium. $\mathbf{b}$ Each line on the graph represents probability of acceptance of UMECNI compared to tiotropium under a particular scenario at multiple thresholds of willingness to pay

\section{Model predictions}

In the base case, UMEC/VI resulted in 5.35 moderate exacerbations and 4.32 severe exacerbations per patient over patient lifetime. The corresponding predictions for tiotropium were 5.35 and 4.30, respectively. The FEV1 benefit of UMEC/VI resulted in an estimated annual exacerbation reduction of 0.04 exacerbations per patient. UMEC/VI also resulted in 0.36 incremental life years and 0.18 incremental QALYs compared with tiotropium over patient lifetime (Table 3).

In the base case, the treatment and resource use costs were broadly comparable between the two treatment alternatives. Per-patient costs over patient lifetime were $£ 372.29$ more for UMEC/VI compared to tiotropium. The resultant incremental cost-effectiveness ratio (ICER) was $£ 2087.60$ per QALY. This ICER increased to $£ 3856.87 /$ QALY and $£ 17,540.98 /$ QALY with increase in UMEC/ VI price to $£ 36.85$ (10\% premium to tiotropium) and $£ 62.76$ (equivalent to price of indacaterol plus tiotropium in separate inhalers), respectively. At a willingness to pay of $£ 20,000$ per QALY, the probability of UMEC/VI being cost-effective was $84.9 \%$. This changed to $72.9 \%$ and $22.9 \%$ as the price of UMEC/VI increased to $£ 36.85$ and $£ 62.76$, respectively (Fig. 2b).

Reducing the model timeframe to 1 year (Scenario A) and 5 years (Scenario B) resulted in improvements in ICER for UMEC/VI. In Scenario A, UMEC/VI resulted in 0.04 fewer exacerbations and 0.01 incremental QALYs compared to tiotropium. UMEC/VI also resulted in lower annual treatment cost of $£ 0.89$, thereby dominating tiotropium. In Scenario B, UMEC/VI predicted 0.04 fewer exacerbations per year, 0.04 incremental QALYs, and an ICER of $£ 567.04$ per QALY. UMEC/VI in Scenario $C$, which assumed treatment benefit for a period of 12 months from treatment initiation, resulted in 0.01 fewer exacerbations, 0.01 incremental QALYs and $£ 3.67$ lower costs resulting in UMEC/VI dominating tiotropium. At a willingness to pay threshold of $£ 20,000$ per QALY, the probability of UMEC/VI being cost-effective was 93.1, 93.0 and $90.0 \%$ for Scenarios A, Scenario B and Scenario C, respectively.

\section{Discussion}

Economic assessments in COPD have demonstrated combination therapies to be cost-effective in the past, but the results have often been inconsistent and depend on the choice of products in the combination and the comparators. Friedman et al. reported that the combination of albuterol and ipratropium is associated with lower rates of exacerbations and is more cost-effective than either drug as monotherapy [27]. Similarly, fluticasone and salmeterol combination therapy was found to be cost-effective in comparison to ipratropium alone [28], ipratropium/albuterol (IPA), and tiotropium alone [29]. However, the combination of tiotropium and salmeterol was not an economically attractive alternative to tiotropium monotherapy [30]. Therefore, it was important to assess the cost-effectiveness of UMEC/VI, a new combination bronchodilator compared with tiotropium, which is the current standard of care in symptomatic COPD patients.

UMEC/VI has been shown to be an efficacious treatment compared with tiotropium [13, 14]. This study assessed the cost-effectiveness of UMEC/VI versus tiotropium monotherapy by using a treatment-specific COPD economic model. The model was based on robust long-term multicentre studies in COPD such as the ECLIPSE [19] and Towards a Revolution in COPD Health (TORCH) [31] and was further validated using Understanding Potential Long-term Impacts on Function with Tiotropium (UPLIFT) study results [32]. In addition, extensive internal and external validation was undertaken 
Table 3 Cost effectiveness of UMEC/VI compared with tiotropium

\begin{tabular}{llc}
\hline Scenario & Incremental QALYs & Incremental costs \\
\hline Base case & 0.18 & $£ 372.29$ \\
UMECNI price = tiotropium + 10\% & 0.18 & $£ 687.81$ \\
UMECNI price = tiotropium + indacaterol & 0.18 & $£ 3128.15$ \\
Scenario A & 0.01 & $-£ 0.89$ \\
Scenario B & 0.04 & $£ 22.69$ \\
Scenario C & 0.01 & $-£ 3.67 .60$
\end{tabular}

ICER incremental cost-effectiveness ratio, $Q A L Y$ quality-adjusted life year, UMECNI umeclidinium bromide-vilanterol

to assess its suitability to COPD patient populations likely to receive a combination bronchodilator such as UMEC/ VI in clinical practice. Overall, the model demonstrated acceptable content and predictive validity.

The model framework allowed FEV1 benefit observed in the clinical trial programme for UMEC/VI to predict long-term outcomes such as exacerbations, mortality and health status. Results suggested small improvements in exacerbation rates and QALYs for UMEC/VI compared with tiotropium. This is not surprising when considering that the patient cohort had low risk of exacerbations with moderate disease severity and dyspnoea. This coupled with low to medium correlation between FEV1 and patient-reported outcomes may not have allowed treatment effect to be completely translated into patientreported outcomes. The model allows treatment effect to be applied based on SGRQ and to test this hypothesis we used results from one of the UMEC/VI studies where UMEC/VI demonstrated significant benefit compared with tiotropium [14]. The model predicted higher QALY benefit (0.35 vs 0.18$)$ and, therefore, more favourable outcome for UMEC/VI when treatment effect on SGRQ was used instead of FEV1. However, we did not use these results in our base case as SGRQ was not the primary endpoint in UMEC/VI clinical studies and UMEC/VI benefit over tiotropium was not always significant $[13,14]$.

A key assumption in the model was the duration of the treatment effect. In the base case, we assumed the treatment effect to continue over the lifetime of the patient. This is in line with the other published COPD models in literature [33]. A scenario analysis assuming a shorter duration of treatment effect of 12 months was also performed. This choice of duration was based on UMEC/ VI safety study [23], which demonstrated the benefit of UMEC/VI on lung function up to 12 months after treatment initiation. Results showed that UMEC/VI ICER improved with a shorter treatment effect than when the treatment effect lasted over patient lifetime. This counterintuitive finding may be a result of patients in UMEC/ VI treatment arm living longer and, thereby, incurring higher costs later in their life.

\section{Limitations}

COPD is a chronic progressive condition, and patients with COPD frequently undergo treatment switches or escalations. In the current analysis, we did not consider any treatment changes. A combination therapy such as UMEC/VI is a new class of combination bronchodilators currently being introduced, and its impact on the treatment pathway is yet unknown. In addition, we assumed that any changes to patient therapy will be similar in UMEC/VI and tiotropium treatment arms such that there will be no additional benefit of UMEC/VI in delaying treatment escalation. We believe that this is a conservative assumption and unlikely to significantly impact final conclusions.

\section{Conclusion}

Overall, UMEC/VI can be considered a cost-effective alternative to tiotropium. Further evidence on UMEC/ VI is needed to assess its long-term benefit for COPD patients. Along with other dual bronchodilators, this may provide additional options in the armamentarium to physicians for COPD patients in need of bronchodilator treatment.

\section{Additional file}

Additional file 1: Table S1. List of risk equations incorporated into the disease progression model (linked-equation model).

\section{Abbreviations}

COPD: chronic obstructive pulmonary disease; DALYs: disability-adjusted life years; EQ-5D: EuroQol 5 dimension; ECLIPSE: Evaluation of COPD Longitudinally to Identify Predictive Surrogate Endpoints; FEV1: forced expiratory volume in $1 \mathrm{~s}$; GOLD: Global Initiative for Chronic Obstructive Lung Disease; ICERs: incremental cost-effectiveness ratios; IPA: ipratropium/albuterol; LAMA: longacting muscarinic antagonist; LABA: long-acting $\beta 2$-agonist; 6MWT: 6-minute walk test; mMRC: modified Medical Research Council scale; NHS: National Health Services; QALYs: quality-adjusted life years; SGRQ-C: St George's Respiratory Questionnaire for COPD; TORCH: Towards a Revolution in COPD Health; UMECNI: umeclidinium bromide and vilanterol combination; UPLIFT: Understanding Potential Long-term Impacts on Function with Tiotropium.

\section{Authors' contributions}

YSP made substantial contributions to conception and design, data analysis and interpretation, manuscript/article preparation, manuscript/article revision 
in terms of important intellectual content, fund acquisition, data collection, and general supervision of the research group. Al made substantial contributions to conception and design, data acquisition, data analysis and interpretation, manuscript/article preparation, manuscript/article revision in terms of important intellectual content, fund acquisition, data collection, and general supervision of the research group. GR made substantial contributions to conception and design, data analysis and interpretation, manuscript/article revision in terms of important intellectual content, fund acquisition, data collection, and general supervision of the research group. MOL made substantial contributions to conception, design and interpretation, has contributed towards manuscript/article preparation, manuscript/article revision in terms of important intellectual content, fund acquisition, data collection, and general supervision of the research group.

\section{Author details}

${ }^{1}$ Value Evidence and Outcomes, GlaxoSmithKline R\&D, Stockley Park, Uxbridge UB1 1 1BT, UK. ${ }^{2}$ Double Helix Consulting, London W1 U 6TQ, UK ${ }^{3}$ Value Evidence and Outcomes, GlaxoSmithKline R\&D, RTP, Durham, NC 27709-3398, USA. ${ }^{4}$ Clinical Epidemiology and Biostatistics, McMaster University, Hamilton, ON L8S 4L8, Canada.

\section{Acknowledgements}

This study was funded by GlaxoSmithKline. All listed authors met the criteria for authorship set forth by the International Committee for Medical Journal Editors. Editorial support, in the form of development, assembling tables and figures, collating author comments, copyediting, fact checking and referencing was provided by Dr. Annirudha Chillar of Cactus Communications Inc. and funded by GlaxoSmithKline. Graeme Roberts and Martin O'Leary are former employees of Double Helix Consulting.

\section{Financial support}

Funding for this study was provided by GlaxoSmithKline.

\section{Competing interests}

YSP and Al are employees of GlaxoSmithKline and hold stocks in GlaxoSmithKline. MOL received project funding from GSK for this study and holds stocks at GSK. GR received project funding from GSK to develop model and conduct analyses.

\section{Received: 9 July 2015 Accepted: 1 December 2015}

Published online: 12 December 2015

\section{References}

1. Global Initiative for Chronic Obstructive Lung Disease (GOLD). Global strategy for the diagnosis, management, and prevention of chronic obstructive pulmonary disease. 2014. Available from http://www.goldcopd.org/uploads/users/files/GOLD_Report2014_Feb07.pdf. Accessed 15 March 2014.

2. WHO methods and data sources for global causes of death 2000-2011. Global Health Estimates Technical Paper WHO/HIS/HSI/GHE/2013.3. Available from http://www.who.int/healthinfo/statistics/GlobalCOD_method. pdf. Accesssed 16 April 2014.

3. United Nations, Department of Economic and Social Affairs, Population Division. World Population Prospects—the 2010 revision. New York, United Nations, 2011. Available from http://esa.un.org/wpp/documentation/pdf/WPP2010_Volume-I_Comprehensive-Tables.pdf. Accessed 15 April 2014.

4. National Institute for Health and Clinical Excellence (NICE). Quality and outcomes framework indicator development programme. Chronic obstructive pulmonary disease: Cost impact statemnt; Implementing NICE guidance July 2012. Available from http://www.nice.org.uk/nicemedia/live/13809/60070/60070.pdf. Accessed 15 March 2014].

5. WHO methods and data sources for global burden of disease estimates 2000-2011. Global Health Estimates Technical Paper WHO/HIS/HSI/ GHE/2013.4. Available from http://www.who.int/healthinfo/global_burden_disease/estimates_regional/en/index1.html. Accessed 15 April 2014.

6. Fletcher MJ, Upton J, Taylor-Fishwick J, Buist SA, Jenkins C, Hutton J, et al. COPD uncovered: an international survey on the impact of chronic obstructive pulmonary disease [COPD] on a working age population. BMC Pub Health. 2011;11:612.

7. Cazzola M, Centanni S, Santus P, Verga M, Mondoni M, di Marco F, et al. The functional impact of adding salmeterol and tiotropium in patients with stable COPD. Respir Med. 2004;98:1214-21.

8. Cazzola M, Noschese P, Salzillo A, De Giglio C, D'Amato G, Matera MG. Bronchodilator response to formoterol after regular tiotropium or to tiotropium after regular formoterol in COPD patients. Respir Med. 2005;99:524-8.

9. Tashkin DP, Ferguson GT. Combination bronchodilator therapy in the management of chronic obstructive pulmonary disease. Respir Res. 2013;14:49.

10. Cazzola M, Molimard M. The scientific rationale for combining long-acting beta2-agonists and muscarinic antagonists in COPD. Pulm Pharmacol Ther. 2010;23:257-67.

11. Yu A, Guerin A, Leon DP, Ramakrishnan K, Wu E, Mocarski M, et al. Therapy persistence and adherence in patients with chronic obstructive pulmonary disease: multiple versus single long-acting maintenance inhalers. J Med Econ. 2011;14(4):486-96.

12. Yu A, Guerin A, Leon DP, Ramakrishnan K, Wu E, Mocarski M, et al. Clinical and economic outcomes of multiple versus single long-acting inhalers in COPD. Respir Med. 2011;105:1861-71.

13. DeCramer M, Anzueto A, Kerwin E, Kaelin T, Richard N, Crater G, et al. Efficacy and safety of umeclidinium plus vilanterol versus tiotropium, vilanterol, or umeclidinium monotherapies over 24 weeks in patients with chronic obstructive pulmonary disease: results from two multicentre, blinded, randomised controlled trials. Lancet Respir Med. 2014;2:472-86.

14. Evaluate the spirometric effect (Trough FEV1) of umeclidinium/vilanterol 62.5/25 mcg once daily compared with tiotriopium $18 \mathrm{mcg}$ once daily over a 24-week treatment period in subjects with COPD (ZEP117115). Available from http://clinicaltrials.gov/ct2/show/record/NCT01777334?te $r m=117115 \&$ rank=1. Accessed 15 April 2014.

15. Yohannes AM, Connolly MJ, Hanania NA. Ten years of tiotropium: clinical impact and patient perspectives. Int J Chron Obstruct Pulmon Dis. 2013:8:117-25.

16. Briggs A, Baker T, Risebrough NA, et al. Developing a new model of COPD from conceptualisation to implementation to validation (GHO-11-5102). In: Presented at the International Society for Pharmacoeconomics and Outcomes Research (ISPOR)—18th International Meeting. 2013 (Abstract).

17. Tabberer M, Gonzalez-McQuire S, Muellerova H, et al. Development of a conceptual model for use in economic modelling of chronic obstructive pulmonary disease (GHO-11-5101). In: Presented at the International Society for Pharmacoeconomics and Outcomes Research (ISPOR-EU) 15th Annual European Congress. 2012. (Abstract).

18. Agusti A, Calverley PM, Celli B, Coxson HO, Edwards LD, Lomas DA, et al. Characterisation of COPD heterogeneity in the ECLIPSE cohort. Respir Res. 2010;11:122.

19. Exuzides A, Colby C, Briggs A, et al. Statistical modeling of disease progression for chronic obstructive pulmonary disease using data from the ECLIPSE study. Med Decis Making. 2015. doi:10.1177/0272989X15610781

20. Starkie HJ, Briggs AH, Chambers MG, Jones P. Predicting EQ-5D values using the SGRQ. Value Health. 2011;14:354-60.

21. Celli B, Crater G, Kilbride S, Mehta R, Tabberer M, Kalberg CJ, et al. Oncedaily umeclidinium/vilanterol 125/25 mcg in COPD: a randomized, controlled study. Chest 2014. [Epub ahead of print].

22. Donohue JF, Maleki-Yazdi MR, Kilbride S, Mehta R, Kalberg C, Church A. Efficacy and safety of once-daily umeclidinium/vilanterol $62.5 / 25 \mathrm{mcg}$ in COPD. Respir Med. 2013;107:1538-46.

23. A 52-week, multicenter, randomized, double-blind, parallel-group, placebo-controlled study to evaluate the safety and tolerability of GSK573719/GW642444 and GSK573719 in subjects with chronic obstructive pulmonary disease (DB2113359). Available from http://clinicaltrials. gov/ct2/show/NCT01316887?term =umeclidinium+AND+125+\%2F+ $25+m c g+A N D+125+m c g+A N D+52-$ week + .\&rank=2. Accessed 15 April 2014.

24. Society JFCBMAaRP. British National Formulary 65. 2012. Available from http://www.bnf.org/bnf/indexhtm. Accessed 4 Oct 2012

25. National Institute for Health and Clinical Excellence (NICE). Guide to the methods of technology appraisal. Issue date: 04 April 2013 [Internet]. 
London: The Institute; 2013. Available from: http://www.niceorguk/ media/GuideToMethodsTechnologyAppraisal2013D45/1E/pdf. Accessed 15 March 2014

26. Punekar YS, Shukla A, Mullerova H. COPD management costs according to the frequency of COPD exacerbations in UK primary care. Int J Chron Obstruct Pulmon Dis. 2014;9:65-73.

27. Friedman M, Serby CW, Menjoge SS, Wilson JD, Hilleman DE, Witek TJ Jr. Pharmacoeconomic evaluation of a combination of ipratropium plus albuterol compared with ipratropium alone and albuterol alone in COPD. Chest. 1999;115:635-41.

28. Akazawa M, Hayflinger DC, Stanford RH, Blanchette CM. Economic assessment of initial maintenance therapy for chronic obstructive pulmonary disease. Am J Manag Care. 2008;14:438-48.

29. Dalal AA, Petersen H, Simoni-Wastila L, Blanchette CM. Healthcare costs associated with initial maintenance therapy with fluticasone propionate $250 \mathrm{mug} / \mathrm{salmeterol} 50$ mug combination versus anticholinergic bronchodilators in elderly US Medicare-eligible beneficiaries with COPD. J Med Econ. 2009;12:339-47.
30. Najafzadeh M, Marra CA, Sadatsafavi M, Aaron SD, Sullivan SD, Vandemheen $\mathrm{KL}$, et al. Cost effectiveness of therapy with combinations of long acting bronchodilators and inhaled steroids for treatment of COPD. Thorax. 2008:63:962-7.

31. Calverley PM, Anderson JA, Celli B, Ferguson GT, Jenkins C, Jones PW, et al. Salmeterol and fluticasone propionate and survival in chronic obstructive pulmonary disease. N Engl J Med. 2007;356:775-89.

32. Tashkin D, Celli B, Senn S, Burkhart D, Kesten S, Menjoge S, et al. A 4-year trial of tiotropium in chronic obstructive pulomonary disease. N Engl J Med. 2008;359:1543-54.

33. Rutten-van Molken MP. Goossens LM. Cost effectiveness of pharmacological maintenance treatment for chronic obstructive pulmonary disease: a review of the evidence and methodological issues. Pharmacoeconomics. 2012;30:271-302.

\section{Submit your next manuscript to BioMed Central and we will help you at every step:}

- We accept pre-submission inquiries

- Our selector tool helps you to find the most relevant journal

- We provide round the clock customer support

- Convenient online submission

- Thorough peer review

- Inclusion in PubMed and all major indexing services

- Maximum visibility for your research

Submit your manuscript at www.biomedcentral.com/submit
() Biomed Central 